\title{
The Potential of Recycled Aggregates and Coconut Fiber in the Production of Concrete
}

\author{
Stephen Adeyemi Alabi ${ }^{*}$ \\ ${ }^{1}$ Department of Civil Engineering, \\ The Federal University of Technology, Akure, NIGERIA \\ *Corresponding Author
}

DOI: https://doi.org/10.30880/ijie.2020.12.08.029

Received 07 February 2020; Accepted 25 July 2020; Available online 15 September 2020

\begin{abstract}
The high cost of conventional construction materials has led researchers into the search for alternative construction materials that are sustainable and eco-friendly. This study investigates the effect of crushed sandscrete block as recycled fine aggregate (RFA) and crushed abandoned cubes as recycled coarse aggregate (RCA) with constant percentage of coconut fibre $(\mathrm{CF})$ on the properties of the concrete. The normal aggregate concrete (NAC) containing normal aggregate (NA) without the addition of CF was first produced and tested. The second stage involved production of concrete comprising constant percentage of $\mathrm{CF}$ with $25 \%, 50 \%, 75 \%$ and $100 \%$ fine and coarse aggregate replacement by weight with RFA and RCA. Properties of fresh and hardened concrete for all specimen types with standard procedure to obtain an optimum mix design was determined. The results obtained from the study shows that the workability of all the replacements were found to be lower than that of the normal aggregate concrete (NAC). Compressive and splitting tensile strength test showed that at optimum replacement levels of $25 \%$ RCA and $25 \%$ RFA concrete have better strength performance than NAC. The study established that RCA and RFA is capable of partially replacing NA in concrete production in ternary form. The optimum percentage replacement of RCA, RFA and CF should be adhered to for effective performance.
\end{abstract}

Keywords: Sandcrete block, recycled coarse aggregate, coconut fibre, compressive strength, workability

\section{Introduction}

It is well known that concrete is one of the major composites and most widely used material in construction industry. Its primary constituents are cement, fine aggregate (sand) and coarse aggregate (granite) which is bonded together with water. However, the generation of huge quantity of construction and demolition (C\&D) and agricultural wastes that is associated with the activities related to the infrastructural development [1]. Hence, instead of using it for land fill or burning it which may contribution to gas emission, the utilization of the same as a potential substitution of natural aggregate is the best alternative solution. Therefore, it will not only solve the problem of land filling but also reduce its impact on the environment.

Limbachiya, Leelawat \& Dhir [2] conducted an experimental investigation on RAC. The results show that there is no significant difference in strength of concrete compared to that of conventional aggregate concrete which is good agreement with the observations by Murali, Vardhan, Rajan, Janani, Jajan \& Ramya [3] and Lau, Elleithy, Choong, Tze, Lee \& Modhwadia [4]. The density of recycled aggregate concrete is $7 \%$ to $9 \%$ lower and 2 times higher water absorption than that of natural aggregate concrete. Khaldoum [5] conducted an experimental investigation on some of the mechanical properties of RAC as compared to those of the NAC. The compressive strengths and the modulus of elasticity of RAC was only $3 \%$ lower than that of NAC. The coefficient of variation ranged from $2.16 \%$ to $3.27 \%$ with 
an average of $2.73 \%$ for RAC and between $1.87 \%$ and $4.18 \%$ with an average of $2.60 \%$ for NAC.

Rahman, Hamdam \& Zaidi [6] studied the effects of different size of recycled coarse aggregate on compressive strength. It was found that the size of $10 \mathrm{~mm}$ and $14 \mathrm{~mm}$ have similar performance. Jagannadha \& Khan [7] examined the suitability of glass fibres in high strength RAC. In their study, the fresh and hardened state properties of partially replaced RCA, with varying percentages of glass fibres, were compared with the corresponding conventional aggregate concrete. The compressive, split tensile and flexural strengths of M50 grade concrete with $0 \%$ RCA and $50 \%$ RCA increase as the fibre content increased. The optimum mix of all these samples were obtained at $0.03 \%$ of fibre content for both the concretes of $0 \%$ RCA and $50 \%$ RCA.

Kenai \& Debieb $[8$ studied the possibility of using crushed clay bricks as coarse and fine aggregate for a new concrete. Concrete with $25 \%$ and $50 \%$ of recycled aggregates for the coarse and fine aggregates respectively produce concrete with similar characteristics to those of NAC. A substitution of coarse aggregate with crushed fine clay brick up to $40 \%$ had a higher mechanical strength compared to the NAC. Akbari, Arora \& Vakil [9] studied the effect on recycled aggregate on concrete properties. Three different water ratios $0.60,0.52$ and 0.43 and aggregate replacement of $0 \%, 15 \%, 30 \%, 50 \%$ were considered in the experimental program. The results show up to $25 \%$ reduction in compressive strength, $23 \%$ reduction in flexural strength, $26 \%$ reduction in split tensile strength and a noticeable reduction in workability was observed as the percentage aggregate replacement increases. Chetna, Vyas \& Jayeshkumar [10] studied the sustainability of fly ash and RCA in concrete. In their study, fly ash and RCA were used as a partial replacement for cement and NCA. The result of the RAC was found to be better than the NAC.

Ede and Agbede [11] studied the use of CF to the mechanical properties of concrete. Their shows that the addition of a $0.5 \% \mathrm{CF}$ as a constitutive material of concrete affected the rheological properties of the fresh concrete, increased the compressive and flexural strength of concrete by $35.8 \%$ and $22.15 \%$ respectively. It was verified that CF content in the excess of $0.75 \%$ reduces the workability and drastically weakens the compressive and flexural strength of concrete [12]. The test results have shown that $\mathrm{CF}$ at $0.5 \%$ content is optimal for enhancing the rheological and mechanical properties of concrete. The presence of CF significantly improves the toughness and the ductility behavior of concrete [13].

Arul, Vidhya, Karthikeyan, \& Uthayakumar [14] studied on strength of concrete by using recycled aggregate from demolition waste in concrete. The test results for the recycled coarse aggregate and conventional concrete have been examined and compared. It is to be concluded that the compressive strength, split tensile strength and flexural strength are in the decreasing order when the percentage of recycled coarse aggregate replacement increases. The compressive strength was found to be decreased by $10 \%$ for recycled coarse aggregate. The split tensile strength was found to be decreased by $8 \%$ for recycled coarse aggregate. The flexural was found to be decreased by $18 \%$ for recycled coarse aggregate. The compressive strength, split tensile strength and flexural strength for recycled coarse aggregate was more or less same compared to normal concrete when polypropylene fiber is added along with $10 \%$ replacement of cement by silica fume in for recycled coarse aggregate concrete. The compressive strength, split tensile strength and flexural strength for for recycled coarse aggregate was more or less same compared to normal concrete when natural (coir) fibre is added along with $10 \%$ replacement of cement by silica fume in RCA concrete.

All the aforementioned study only considered either the incorporation of RCA or RCA with CF. Therefore, this study presents the potential of recycled aggregates (i.e., crushed sandscrete block as RFA and crushed abandoned cubes as RCA) with constant percent of CF in the production of lightweight concrete. The RCA, RFA and CF have positive effects on the properties of the concrete with added advantage in the reduction of cost of concrete, and waste management.

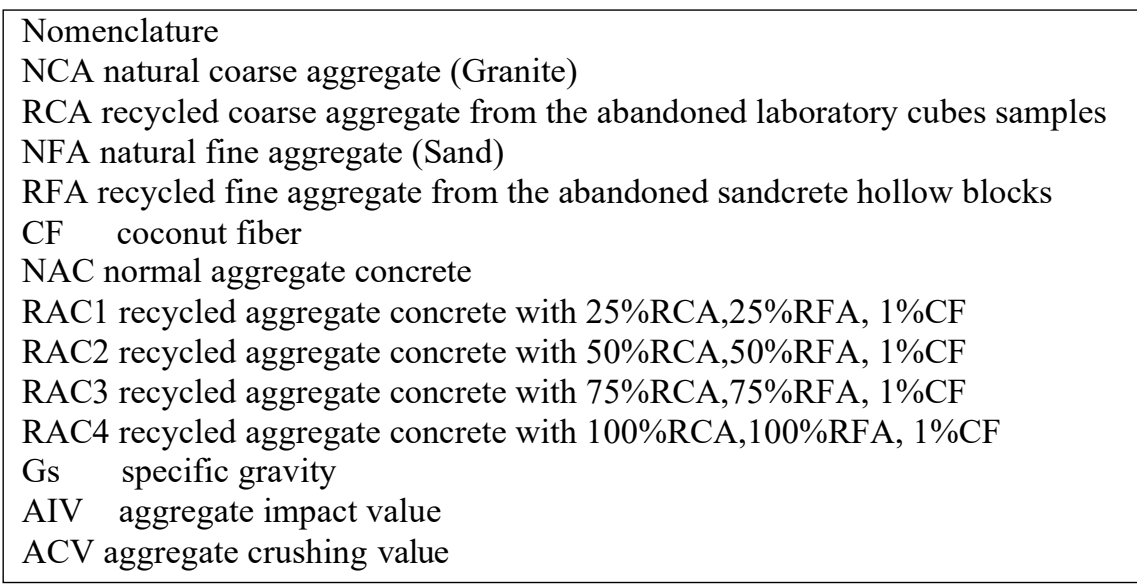




\section{Materials and Methods}

\subsection{Materials}

Sharp sand is used as a fine aggregate in this study (see Fig. 2). This is often mixed with NCA (granite) and ordinary Portland cement (OPC) of grade 32. Fig. 1 shows the particle distribution of sand in accordance to BS 812: Part 104 [15]. However, from the figure, the coefficient of uniformity, $\mathrm{C}_{\mathrm{u}}$ and coefficient of curvature $\left(\mathrm{C}_{\mathrm{c}}\right)$ is obtained to be 5 and 1.09 respectively. Therefore, since, $C_{u}>4$ and $C_{z}=1.09$ which according to the Unified Soil Classification System, the soil infers as poorly graded soil. The fineness modulus, specific gravity, $G_{s}$, bulk density and water absorption are $27.4 \%, 2.34,1390$ and 2.42 respectively. The crushed RFA (see Fig. 3) was obtained from abandoned sandscrete hollow blocks in the structural laboratory, the Federal University of Technology, Akure, Nigeria. One of the usual practices of disposing this waste is by landfilling, which may have impact on the environment. Therefore, this waste is used in this study as a partial replacement for NFA. The particle size distribution is shown in Fig. 1 . The values of $\mathrm{Cu}$ and $\mathrm{Cc}$ were obtained to be 6.25 and 1.42 respectively.

A NCA (crushed granite) (see Fig. 4) with smooth surface sourced from a quarry site in Akure, Nigeria is used in this study. The maximum size of aggregate used is $14 \mathrm{~mm}$. Fig. 1 shows the particle distribution of the NCA. The fineness modulus, specific gravity, bulk density and absorption rate are 5.78, 2.65, 1635 and 1.86 respectively. The coefficient of uniformity, $\mathrm{C}_{\mathrm{c}}$, is 1.93 while coefficient of curvature $\mathrm{C}_{\mathrm{u}}$, is 1.47 . This implies that the aggregate is well graded. In this study, the average value of ACV for NCA is obtained to be 30.4. Also, the AIV values of the normal aggregates is approximately 23. Therefore, the granite used as a coarse aggregate meet the specification for both wearing and non-wearing surface.

RCA (see Fig. 5) was sourced from the abandoned crushed concrete cubes dumped at FUTA) structural laboratory. It consists of crushed concrete aggregate and hardened concrete paste. The compressive strength of the crushed concrete cubes is believed to be within the range of $8 \mathrm{~N} / \mathrm{mm}^{2}$ and $15 \mathrm{~N} / \mathrm{mm}^{2}$. It was crushed manually with the use of hammer and mallet. Prior to the mix design, the RCA was sieved and graded to ensure quality concrete matrix. The gradation of RCA is presented in Fig. 1. Also, in order to reduce the water demand by RCA, all particles less than 4.75 $\mathrm{mm}$ were not used. However, from the practical application point of view, the RCA is directly used in its natural state (i.e., dry state) in the concrete mix. In other words, RCA is used as a partial replacement for NCA in its dry state that is it was neither washed nor pre-saturated.

Coconut fibers were collected from oil producing company in Akure, Nigeria. The shells were then washed properly with clean water and air dried under room temperature and graded in accordance with ASTM C330 [17]. The fibers were chopped with sharp scissors maintaining a length ranging from 12 to $30 \mathrm{~mm}$. The typical chopped CF used in this study is presented in Fig. 6.

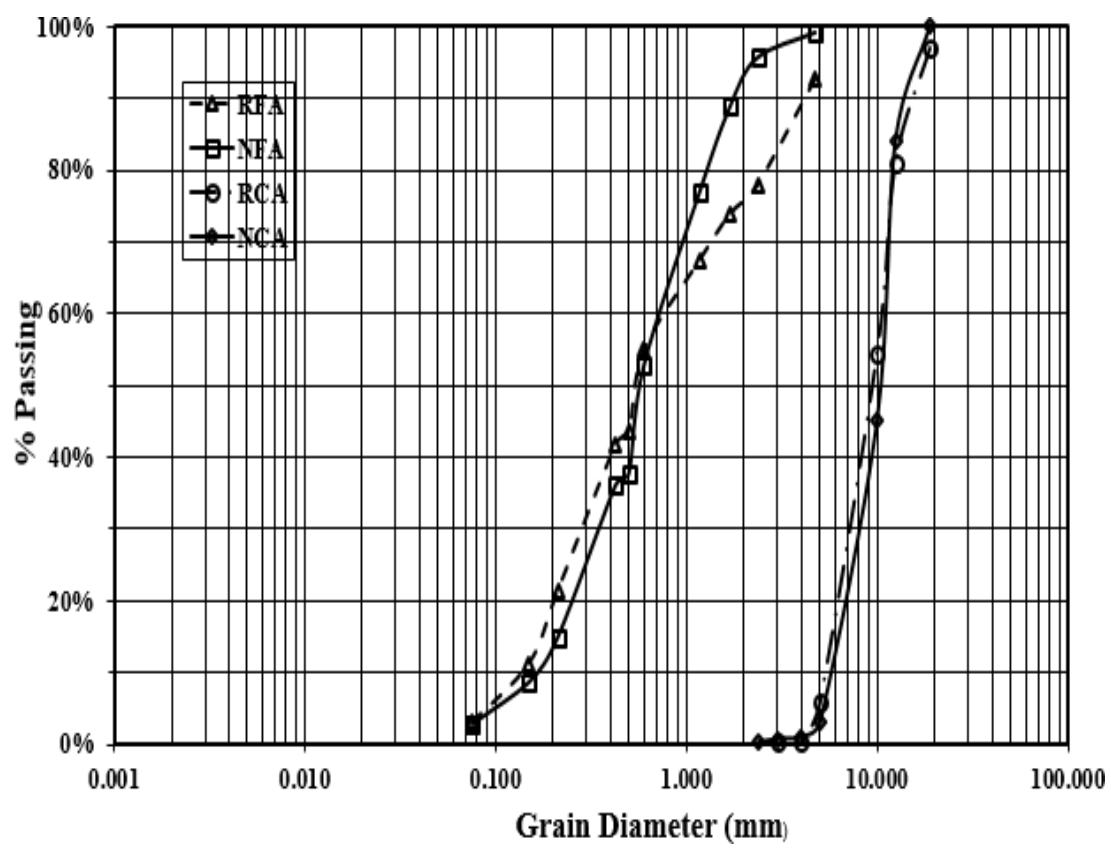

Fig. 1 - Particle size distribution for RFA, NFA, RCA and NCA 


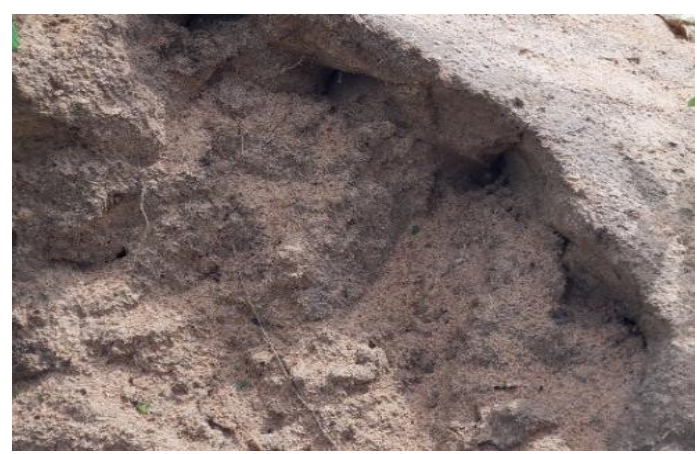

Fig. 2 - Akure Pit-Sand (NFA)

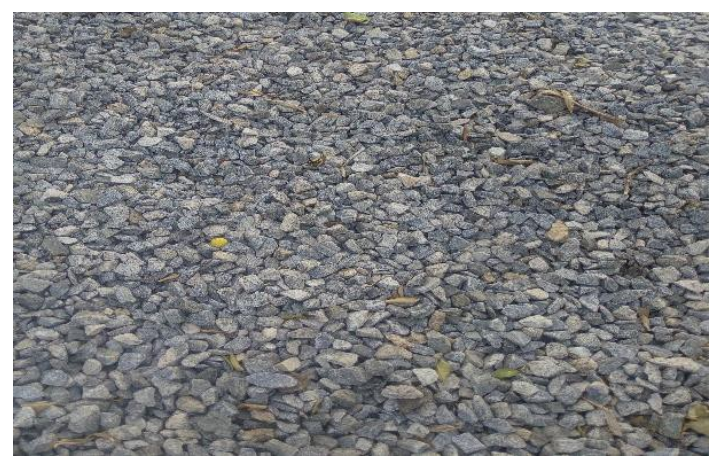

Fig. 4 - Natural Coarse Aggregate (NCA)

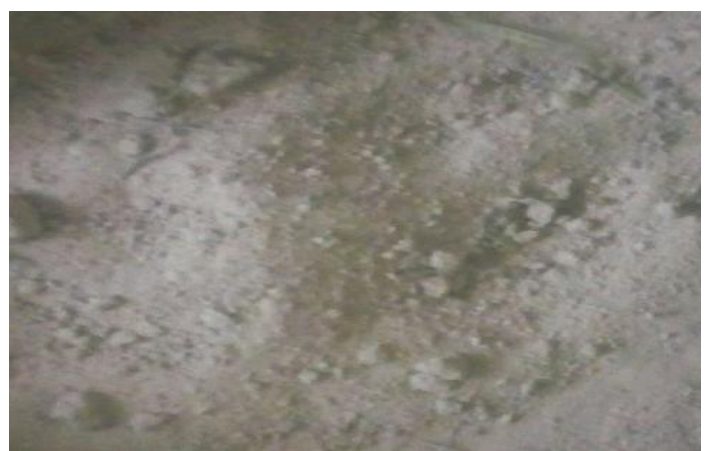

Fig. 3 - Recycled Fine Aggregate (RFA)

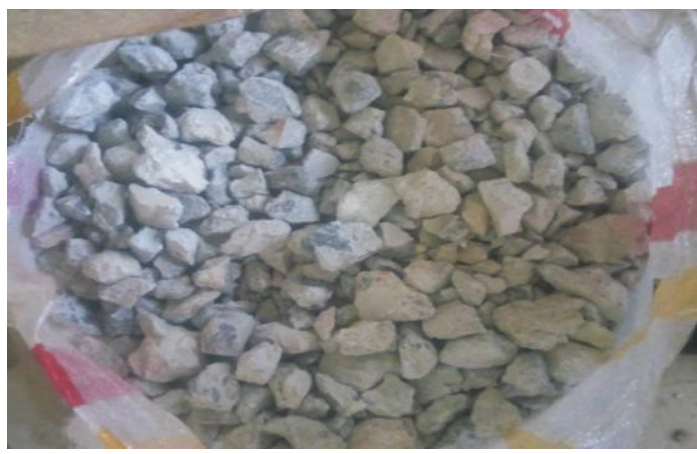

Fig. 5 - Recycled Coarse Aggregate (RCA)

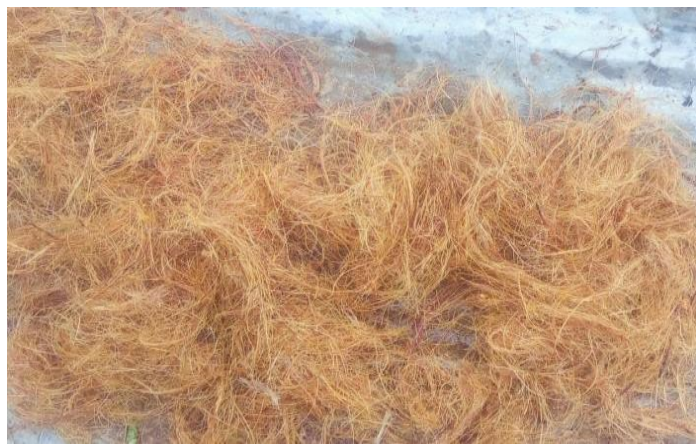

Fig. 6 - Coconut Fiber (CF)

\subsection{Methods}

A mix ratio of 1: 2: 4 with water-cement ratio of 0.50 was used. Five different concrete mix designs were adopted; one NAC and four RAC. Concrete was produced by partially replacement of NFA and NCA with $0 \%, 25 \%, 50 \%, 75 \%$ and $100 \%$ of RFA and RCA at $1 \%$ constant addition of coconut fiber. The mixtures designation and quantities of various materials for each designed concrete mixes are given in Table 1.

Table 1 - Mix proportion of concrete

\begin{tabular}{cccccccc}
\hline \multirow{2}{*}{$\begin{array}{c}\text { Mixture } \\
\text { Identification }\end{array}$} & NCA & RCA & NFA & RFA & Cement & Water & $\begin{array}{c}\text { Additive } \\
\text { (CF) }\end{array}$ \\
\hline Control (Ctrl) & 455.82 & - & 227.91 & - & 113.96 & 62.67 & - \\
RAC1 & 422 & 337.6 & 84.4 & 422 & 211.2 & 126.7 & 1.14 \\
RAC2 & 422 & 253.2 & 168.8 & 422 & 211.2 & 126.7 & 1.14 \\
RAC3 & 422 & 168.8 & 253.2 & 422 & 211.2 & 126.7 & 1.14 \\
RAC4 & 422 & 84.4 & 337.6 & 422 & 211.2 & 126.7 & 1.14 \\
\hline
\end{tabular}


All the samples were prepared in accordance to BS1881: Part 111 [18]. Slump test was carried on the fresh concrete in order to measure it workability. The samples were placed in the concrete molds, free of debris and oil. Care was also taken that there were no gaps, so as to avoid the possibility of leakage from the slurry. After 24 hours, the concrete cubes were removed from the mold, weigh and kept under water in accordance to BS1881: Part111 [18]. After the removal from the water and allow to air-dried, hardened concrete tests such as compressive strength and splitting tensile strength tests was carried out, and analyzed.

\section{Results and Discussion}

\subsection{Slump Test}

The results of slump test carried on the fresh concrete in other to determine its workability rate are presented in Fig. 7. The results show that the slump values decrease as the percentage replacement increases at constant addition of fibers. The decrement in the workability of concrete maybe due to reduction in mobility of material and fibers creates blocking to the relative movement of the aggregates. Therefore, it restrained the concrete mixtures from segregation and flow. From the figure, it can be seen that slump of all the RAC fell within the range of $30 \mathrm{~mm}$ to $60 \mathrm{~mm}$, which implies that the concrete mixes exhibit lower to medium workability. The low workability maybe due to the rapid absorption of the part of mixing water by recycled aggregates.

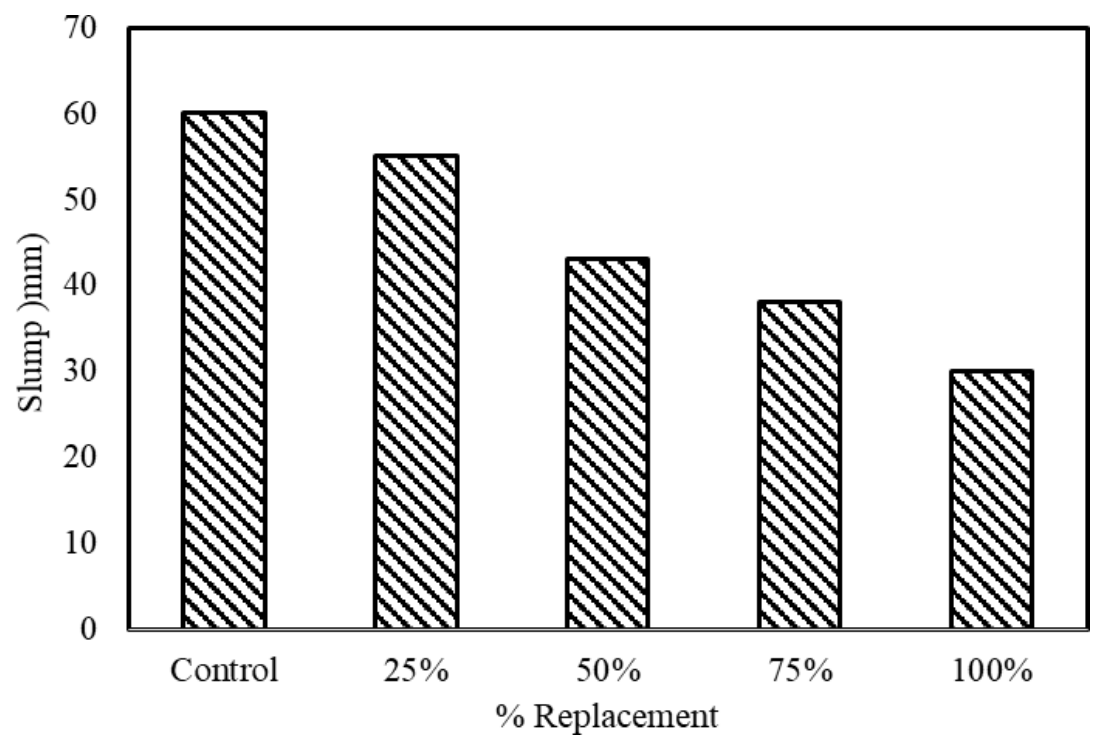

Fig. 7 - The slump values of RAC with percentage of CF

\subsection{Compressive Strength}

The compressive strength was investigated through concrete cubes containing varying percentage replacement of recycled aggregates with a constant addition of coconut fiber. The average results for compressive strength are provided in Fig. 8. As expected, the 7-day concrete cube attained the lowest compressive while the 28-day concrete cube had the highest compressive strength for the concrete mixes. The result shows that the compressive strength increases up to $25 \%$ partial replacement of RFA and RCA with the addition of CF and the rate of decrease in the compressive strength later becomes more rapidly. The maximum compressive strength was recorded as $13.4 \mathrm{~N} / \mathrm{mm}^{2}$ with $1 \%$ inclusion of $\mathrm{CF}$ at 28-day. The sudden decrease in compressive strength maybe due to the unevenly distribution and improper orientation of $\mathrm{CF}$, which unable to resist the propagation of crack and reduced the concrete strength. The low compressive strength of concrete might also be attributed to poor physical and bond properties of the recycled aggregate and CF that is due to potentially degraded bond at interfacial transition zone (ITZ) between the aggregates and the cement matrix. Lower compressive strength can also be explained by smoother surface of NCA and NFA which induced a lower interparticle attrition.

\subsection{Splitting Tensile Strength}

Fig. 9 shows the results of splitting tensile strength of RAC with $0 \%, 25 \%, 50 \%, 75 \%$ and $100 \%$ content of RFA and RCA as NFA and NCA replacement at constant addition of CF for 7-day, 14-day, 14-d and 28-day respectively. It is also evidence from the figure that the concrete has better strength performance at optimum replacement levels of $25 \%$ RCA and 25\% RFA than 100\% NAC and RAC mixes. It is observed from figure, for all the concrete mixture that 
the tensile strength increased almost linearly. Maximum tensile strength was $3.6 \mathrm{~N} / \mathrm{mm}^{2}$ at $25 \%$ of RFA and RCA with constant $\mathrm{CF}$.

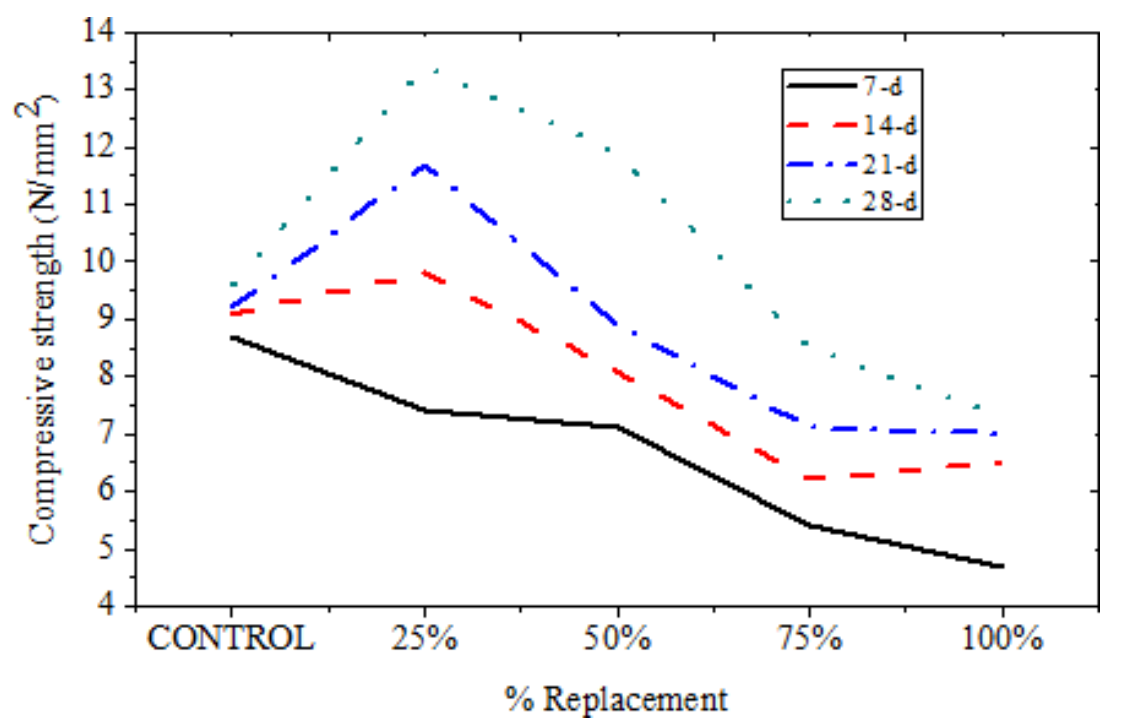

Fig. 8 - Compressive strength development for RCA with CF cured at $27 \pm 2^{\circ} \mathrm{C}$

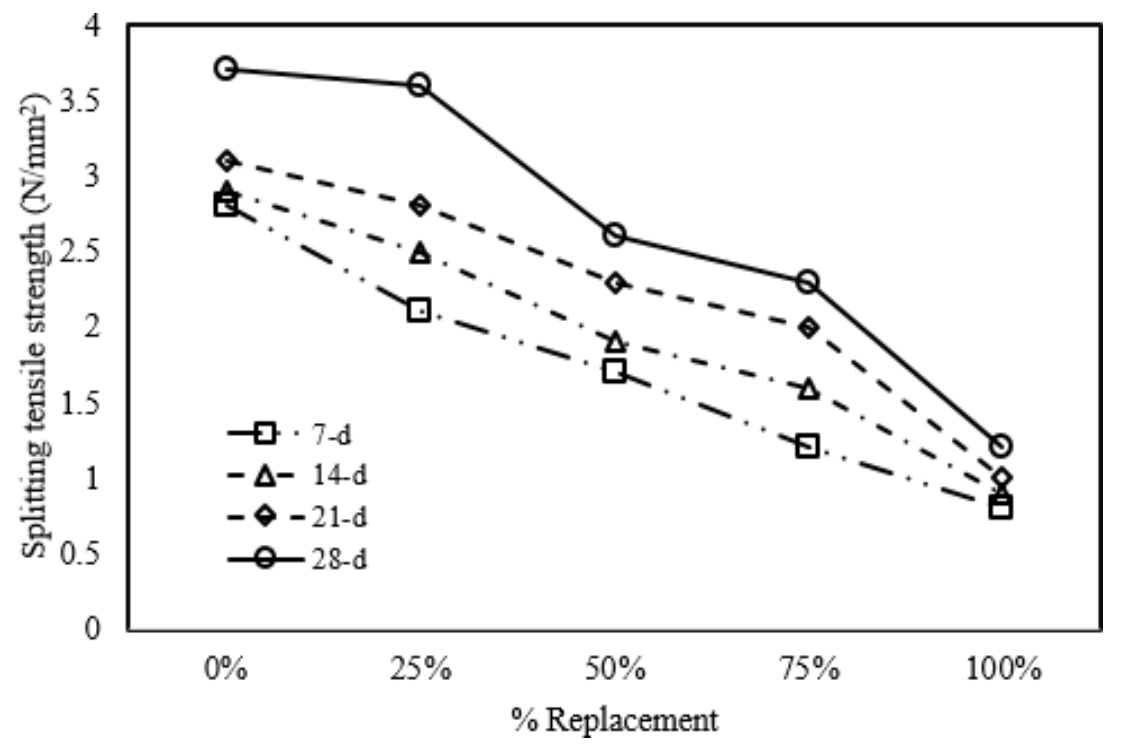

Fig. 9 - Splitting tensile strength development for RCA with CF cured at $27 \pm 2^{\circ} \mathrm{C}$

\section{Conclusion}

This study presents the experimental study on the potential of recycled aggregates (i.e., crushed sandscrete block as RFA and crushed abandoned cubes as RCA) with constant percent of CF in the production of lightweight concrete. The RCA, RFA and CF have positive effects on the properties of the concrete with added advantage in the reduction of cost of concrete, and waste management. From the present study, it can be concluded that the slump result ranging from ( 30 $\mathrm{mm}$ to $60 \mathrm{~mm}$ ) which shows that the workability of concrete reduced as the addition of recycled aggregates with $\mathrm{CF}$ increases due to the dryness of the aggregates. At $25 \%$ increase of recycled aggregates, constant $\mathrm{CF}$ with 0.55 water cement ratio, compressive strength test yielded best result and its tensile strength is a little lower than that of $0 \%$ recycled aggregates.

\section{References}

[1] Hunashikatti, G. M., Pradhan, S. \& Barai, S. V. (2018). Partially hydrated recycled aggregate concrete: A systematic approach towards sustainable development. Construction and Building Materials, 186, 537-549. 
[2] Limbachiya, M. C., Leelawat, T. \& Dhir, R. K. (2000). Use of recycled concrete aggregate in high strength concrete. Materials and Structures, 4(33), 574-580.

[3] Murali1, G., Vardhan, C. M. V., Rajan, G., Janani, G. J., Jajan, N. S. \& Ramya, S. R. (2012). Experimental study on recycled aggregate concrete. International Journal of Engineering Research and Applications, 2(2), 407-410.

[4] Lau, T. L., Elleithy, W., Choong, W. K., Tze, T. Y., Lee, C. M. \& Modhwadia, A. L. (2014). Effects of recycled aggregates on concrete strengths. Materials Research Innovations, 18(6), 370-374.

[5] Khaldoum, R. (2005). Mechanical properties of concrete with recycled coarse aggregate. Construction and Building Materials, 21(2), 277-288.

[6] Rahman, I. A., Hamdam, H. \& Zaidi, A. M. A. (2009). Assessment of recycled aggregate concrete. Applied Science, 3(10), 47-54.

[7] Jagannadha, K. \& Khan, A. (2009). Suitability of glass fibers in high strength recycled aggregate concrete - An Experimental investigation. Asian Journal of Civil Engineering, 10(6), 681-689.

[8] Kenai \& Debeib. (2010). Effect of recycled aggregate on normal strength concrete. International Journal of Advances in Engineering Sciences, 4(4), 35-38.

[9] Akbari, Y. V., Arora, N. K. \& Vakil, M. D. (2011). Effect on recycled aggregate on concrete properties. International Journal of Earth Sciences and Engineering, 4(6), 924-928.

[10] Chetna, M. Vyas, H. \& Jayeshkumar, P. (2013). Fly ash and recycled coarse aggregate in concrete. International Journal of Engineering Trends and Technology, 4(5), 30-38.

[11] Ede, A. \& Agbede, J. O. (2015). Use of coconut husk fiber for improved compressive and flexural strength of concrete. International Journal of Scientific and Engineering Research, 6(2), 968-978.

[12] Hasan, N. M. S., Sobuz, H. R., Sayed, M. S. \& Islam, M. S. (2012). The use of coconut fiber in the production of structural lightweight concrete. Journal of Applied Scince, 12(9), 831-839.

[13] Majid, A., Xiaoyang, L., \& Nawawi, C., (2013). Experimental investigations on bond strength between coconut fibre and concrete. International Journal of Research in Engineering and Technology, 6(3), 596-605.

[14] Arul, R., Vidhya, A., Karthikeyan, K. \& Uthayakumar, P. (2016). Study on strength of concrete by using recycled aggregate from demolition waste in concrete. International Journal of Research in Engineering and Technology, 5(6), 176-181.

[15] British Standard Institution 812 (1985). Testing Aggregates, Part 104: Methods for Determination of Particle Size Distribution - Section 103.1 Sieve Tests. Published under the authority of the Board of BSI, The Direction of the Cement, Gypsum, Aggregates and Quarry Products Standards Committee, London, United Kingdom.

[16] British Standard Institution, 882 (1992). Aggregate from natural sources for concrete. Published under the authority of the Board of BSI, the direction of the Cement, Gypsum, Aggregates and Quarry Products Standards Committee, London, United Kingdom.

[17] ASTM C330 (2009). Standard specification for lightweight aggregate for structural concrete. Annual Book of ASTM Standards.

[18] British Standard Institution 1881 (1983). Testing concrete, Part 111: Method for making test cubes from fresh concrete. Published under the authority of the Board of BSI, The Direction of the Cement, Gypsum, Aggregates and Quarry Products Standards Committee, London, United Kingdom. 